Article

\title{
Comparative Analysis of Amaryllidaceae Alkaloids from Three Lycoris Species
}

\author{
Yongqiang Tian ${ }^{1,2}$, Chunyun Zhang ${ }^{1}$ and Mingquan Guo ${ }^{1, *}$ \\ Received: 8 November 2015 ; Accepted: 30 November 2015 ; Published: 7 December 2015 \\ Academic Editor: Marcello Iriti \\ 1 Sino-Africa Joint Research Center/Key Laboratory of Plant Germplasm Enhancement and Specialty \\ Agriculture, Wuhan Botanical Garden, Chinese Academy of Sciences, Wuhan 430074, China; \\ xiaoqiangtian2013@163.com (Y.T.); cyzhang@wbgcas.cn (C.Z.) \\ 2 Graduate University of Chinese Academy of Sciences, Beijing 100049, China \\ * Correspondence: guomq@wbgcas.cn; Tel./Fax: +86-27-8751-8018
}

\begin{abstract}
The major active constituents from Amaryllidaceae family were reported to be Amaryllidaceae alkaloids (AAs), which exhibited a wide spectrum of biological activities, such as anti-tumor, anti-viral, and acetyl-cholinesterase-inhibitory activities. In order to better understand their potential as a source of bioactive AAs and the phytochemical variations among three different species of Lycoris herbs, the HPLC fingerprint profiles of Lycoris aurea (L. aurea), L. radiata, and L. guangxiensis were firstly determined and compared using LC-UV and LC-MS/MS. As a result, 39 peaks were resolved and identified as AAs, of which nine peaks were found in common for all these three species, while the other 30 peaks could be revealed as characteristic AAs for L. aurea, L. radiata and L. guangxiensis, respectively. Thus, these AAs can be used as chemical markers for the identification and quality control of these plant species. To further reveal correlations between chemical components and their pharmaceutical activities of these species at the molecular level, the bioactivities of the total AAs from the three plant species were also tested against HepG2 cells with the inhibitory rate at $78.02 \%, 84.91 \%$ and $66.81 \%$ for L. aurea, L. radiata and L. guangxiensis, respectively. This study firstly revealed that the three species under investigation were different not only in the types of AAs, but also in their contents, and both contributed to their pharmacological distinctions. To the best of our knowledge, the current research provides the most detailed phytochemical profiles of AAs in these species, and offers valuable information for future valuation and exploitation of these medicinal plants.
\end{abstract}

Keywords: Amaryllidaceae alkaloids; chemical fingerprints; chemical marker; anti-HepG2 activity

\section{Introduction}

Belonging to the Amaryllidaceae family, plants of genera Lycoris were known not only for their ornamental value, but also for their medicinal value being used as a medicinal herb for thousands of years in China [1,2]. It has been well documented that the Amaryllidaceae alkaloids (AAs) were responsible for their pharmaceutical activities, and exhibited a wide spectrum of biological activities, such as anti-tumor, anti-malarial, and acetylcholinesterase inhibitory activities [3-8]. In turn, there has been growing interest in the search for new AAs with better bioactivities from Amaryllidaceae plants [9]. In the past few years, more and more alkaloids were isolated from the Amaryllidaceae family, and most of which belong to galanthamine type, lycorine type, homolycorine type, tazettine type and crinine type in terms of chemical structures [10]. Among them, galanthamine and lycoramine were reported to exhibit good activity against Alzheimer's disease [7]. While more AAs, such as lycorine, dihydrolycorine, haemanthamine, pretazettine, pseudolycorine, and narciclasine, 
showed significant activity against a variety of cancer cells either by inhibiting cancer cell growth mainly through cytostatic effects targeting small RHO GTPases or through the inhibition of protein synthesis and the subsequent disorganization of the actin cytoskeleton [11-14]. Due to the remarkable pharmaceutical activities, AAs have led to increasing interest in the search for new resources and new bioactive components from different species in the Amaryllidaceae family. However, most of the current research only focused on certain major species on the market, and little work has been conducted for the comprehensive analysis of AAs from different Lycoris species. Since remarkable chemical differences have often been found in different species of medicinal plants or even from different geographic origins, which significantly affected quality and bioactivities. In most cases, the chemical differences often resulted in pharmacological distinctions. In this context, we set out to investigate and compare chemical fingerprint profiles of three Lycoris species. Due to the complexity and variety of components in these plant species, it is of primary importance to develop a tailored analytical method for the comprehensive analysis of AAs from these medicinal plants $[15,16]$.

In the past few decades, a number of analytical methods including GC-MS, LC-MS, and CE-ESI-IT-MS have been developed for the analysis of AAs [17-23], which contributed significantly to the better understanding of AAs from medicinal plants. Due to the high sensitivity and the access to the MS database, GC-MS was deemed as an effective method for the analysis of AAs in the past [19]. However, it was limited to AAs with relatively higher volatility, which was inappropriate to some AAs, especially in this work. Compared to GC-MS, LC-MS has been more widely used in the analysis of alkaloids in various plant sources due to its ability in detecting thermo-unstable and high-molecular-weight alkaloids in recent years [19,21], and it is thus applied in this study. While used for different research purposes, those LC-MS methods reported have limitations in both their resolution and capacity of profiling AAs, and can only analyze one or a very limited number of AAs [23-27]. In order to conduct a comprehensive analysis of AAs, and overcome these limitations, a more effective method is required to compare fingerprint profiles of different Lycoris species. Thus, a rapid, sensitive, and reliable HPLC-UV/ESI-MS/MS method has been successfully developed for the comparative analysis of the AAs from different Lycoris species, which resulted in the simultaneous separation and identification of over 30 AAs from different Lycoris species under the optimized conditions. To the best of our knowledge, the present study is the first report on qualitative and quantitative assessment of AAs from different Lycoris species, and provides an important clue for future valuation and exploitation of these medicinal plants.

\section{Results and Discussion}

\subsection{Optimization of Chromatographic Conditions}

Previous phytochemical investigations into AAs in Lycoris species revealed its complexity in chemical structure and the diversity in AAs types, e.g., galanthamine, galanthine, lycorine, lycoramine, narwedine, tazettine, and haemanthamine $[17,18]$. This posed significant challenges to the comprehensive analysis of AAs from different species. Considering the structural differences of AAs and other reported LC methods, chromatographic conditions, such as wavelength of maximum absorption, LC columns, mobile phase and mobile phase additives, were systematically investigated to achieve better separation of AAs. By scanning the samples extracted from different species, the maximum absorption wavelength at $232 \mathrm{~nm}$ was selected for LC-UV analysis in this study. Based on the column efficiency, and the resultant chromatograms, Phenomenex ODS column $(150 \times 2.00 \mathrm{~mm}, 5 \mu \mathrm{m}$, Phenomenex, Torrance, CA, USA) was chosen as a preferred one over the reverse phase C18 column (Sunfire C18, $150 \mathrm{~mm} \times 4.6 \mathrm{~mm}, 3.5 \mu \mathrm{m}$, Waters, Milford, MA, USA). By stepwise investigation of mobile phase and additives, including methanol-water, acetonitrile-water, acetonitrile- $0.1 \%$ formic acid, acetonitrile- $10 \mathrm{mM}$ ammonium acetate, and acetonitrile- $40 \mathrm{mM}$ ammonium acetate, the combination of acetonitrile and $40 \mathrm{mM}$ ammonium acetate was chosen as the mobile phase and additives according to their better performance and resolution 
in the gradient elution at $232 \mathrm{~nm}$, respectively. The final optimized conditions for the analysis of AAs from different Lycoris species are given in Section 3.3.1.

\subsection{Sample Analysis and Amaryllidaceae Alkaloids' (AAs) Identification}

\subsubsection{HPLC Fingerprint Profiles}

Total AAs extracted from the bulks of the three Lycoris species were further enriched by Oasis MCX SPE cartridges, and subsequently analyzed in parallel on a Phenomenex column under the optimized LC conditions. As shown in Figure 1a-c, the HPLC fingerprinting profiles of AAs from the three species were determined. It was observed that 39 peaks were well resolved under the given HPLC conditions, indicating that the optimized conditions were achieved for the comparative analysis of AAs from the three Lycoris species.

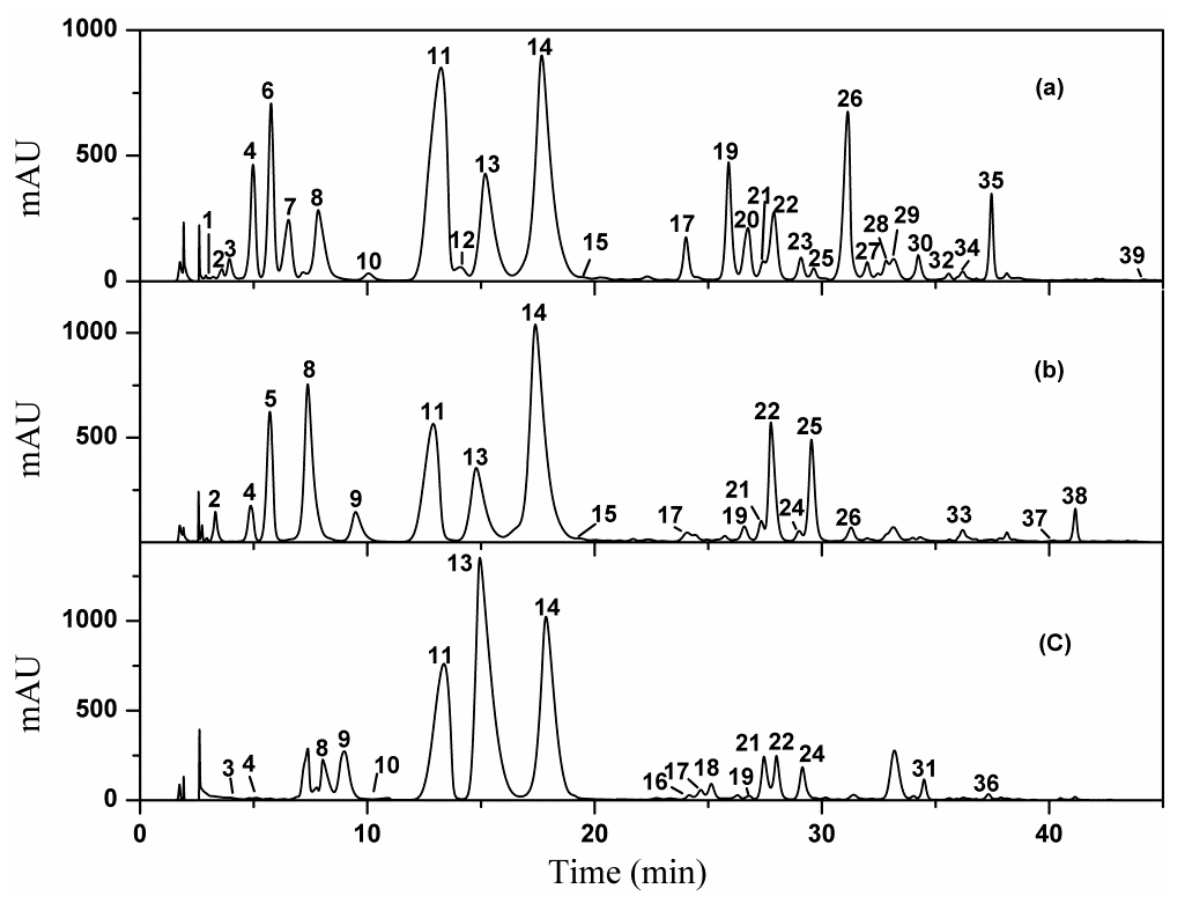

Figure 1. HPLC profiles of L. radiata (a); L. aurea (b) and L. guangxiensis (c).

\subsubsection{Identification of AAs}

According to the HPLC profiles (Figure 1), 39 AAs were detected from the three Lycoris species, which were listed in Table 1. Among them, 29 AAs were identified in this study by comparing their MS/MS with the corresponding authentic standards or published literatures as shown in Table 1. To the best of our knowledge, seven of the AAs (labeled as "a" in Table 1) were firstly reported in genera Lycoris, and five of them (labeled as " $b$ " in Table 1) were firstly reported in the Amaryllidaceae family. Based on the identifications, the chemical structures of the 29 AAs were summarized in Figure 2. Since different types of AAs displayed different fragment pathways using ESI-MS/MS, the structural diversity of AAs made their identification very complicated. To simplify the interpretation of the obtained MS/MS data for AAs, we classified them into five groups according to their chemical structures, i.e., galanthamine type, lycorine type, crinine type, homolycorine type and tazettine type $[17,24,25]$. In more detail, the representative interpretations of the MS/MS data for five alkaloid types were discussed as below. 


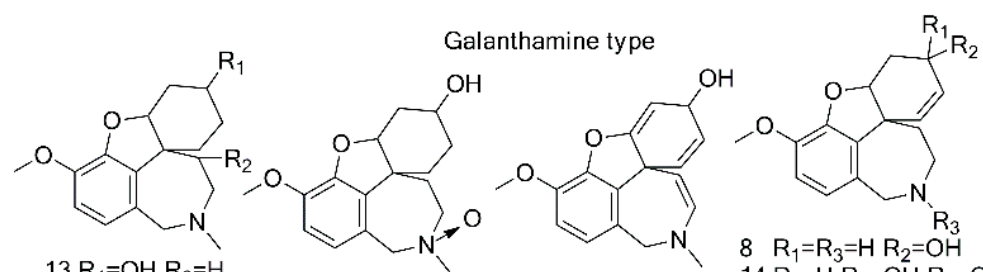

$13 \mathrm{R}_{1}=\mathrm{OH} \mathrm{R}_{2}=\mathrm{H}$ $31 \mathrm{R}_{1}=\mathrm{R}_{2}=\mathrm{OCH}_{3}$

15

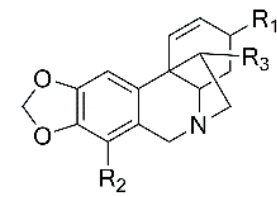

$20 \mathrm{R}_{1}=\mathrm{R}_{2}=\mathrm{OCH}_{3} \mathrm{R}_{3}=\mathrm{OH}$ $21 \mathrm{R}_{1}=\mathrm{OH} \mathrm{R} \mathrm{R}_{2}=\mathrm{R}_{3}=\mathrm{H}$ $25 \mathrm{R}_{1}=\mathrm{OCH}_{3} \mathrm{R}_{2}=\mathrm{H} \mathrm{R} \mathrm{R}_{3}=\mathrm{OH}$<smiles>[R2]C1([R])OC2C(F)C=C3CCN(C)C3C2c2cc3c(cc21)OCO3</smiles>
$19 \mathrm{R}_{1}=\mathrm{R}_{3}=\mathrm{H} \mathrm{R}_{2}=\mathrm{OH}$ $26 \mathrm{R}_{1}=\mathrm{OH} \mathrm{R} \mathrm{R}_{2}+\mathrm{R}_{3}=\mathrm{O}$ $27 \mathrm{R}_{1}=\mathrm{OH} \mathrm{R}_{2}=\mathrm{H} \mathrm{R}_{3}=\mathrm{OCH}_{3}$ $30 \mathrm{R}_{1}=\mathrm{OCH}_{3} \mathrm{R}_{2}=\mathrm{H} \mathrm{R} \mathrm{R}_{3}=\mathrm{OH}$ $36 \mathrm{R}_{1}=\mathrm{R}_{3}=\mathrm{OCH}_{3} \mathrm{R}_{2}=\mathrm{H}$

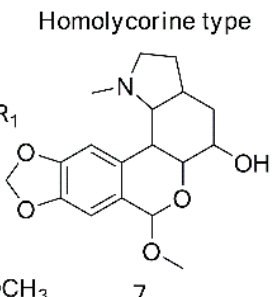
7<smiles>OC1C=CC23CC1N(Cc1cc4c(cc12)OCO4)C3</smiles>
2
$14 \mathrm{R}_{1}=\mathrm{H} \mathrm{R}_{2}=\mathrm{OH} \mathrm{R} \mathrm{R}_{3}=\mathrm{CH}_{3}$ $24 \mathrm{R}_{1}+\mathrm{R}_{2}=\mathrm{O} \mathrm{R}_{3}=\mathrm{CH}_{3}$

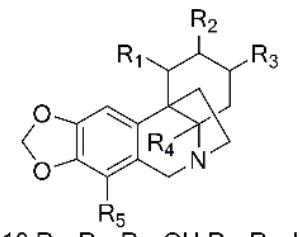

$10 \mathrm{R}_{1}=\mathrm{R}_{2}=\mathrm{R}_{4}=\mathrm{OH} \mathrm{R}_{3}=\mathrm{R}_{5}=\mathrm{H}$ $22 \mathrm{R}_{1}+\mathrm{R}_{2}=\mathrm{OR}_{3}=\mathrm{OHR}_{4}=\mathrm{H} \mathrm{R}_{5}=\mathrm{OCH}_{3}$

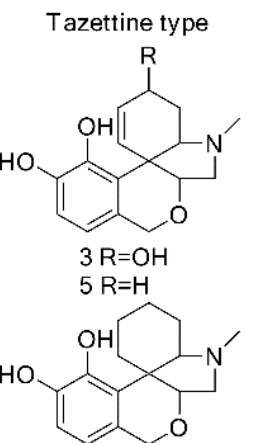<smiles>O=c1c2cc3c(cc2c2cccc4ccn1c42)OCO3</smiles>

$11 \mathrm{R}_{1}=\mathrm{OH} \mathrm{R} \mathrm{R}_{2}+\mathrm{R}_{3}=\mathrm{CH}_{2}$<smiles>OC1CC2CCN3Cc4cc5c(cc4C(C1O)C23)OCO5</smiles>

Lycorine type

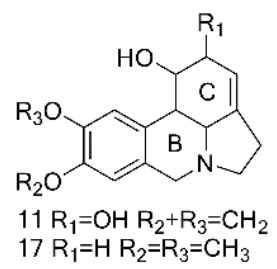<smiles>OC1C=C2CC[N+]3=Cc4cc5c(cc4C(C1O)C23)OCO5</smiles>

12

Figure 2. Chemical structures of the AAs identified from L. aurea, L. radiata and L. guangxiensis (Note: the numbers correspond to the peak numbers shown in Figure 1).

Table 1. Peaks detected as AAs by LC-MS/MS.

\begin{tabular}{|c|c|c|c|c|c|}
\hline $\begin{array}{l}\text { Peak } \\
\text { No. }\end{array}$ & $\begin{array}{c}R_{t} \\
(\min )\end{array}$ & $\begin{array}{c}\text { PI-MS } \\
{[\mathbf{M}+\mathbf{H}]^{+}}\end{array}$ & MS/MS Data & Identification & Alkaloid Type/Ref \\
\hline 1 & 3.22 & 284 & $266,256,249,241,237,226,213,199$ & 1,11-didehydrogalanthamine ${ }^{b}$ & GA [17] \\
\hline 2 & 3.61 & 304 & $286,268,250,227,211,150$ & 11-hydroxyvittatine $\mathrm{N}$-oxide ${ }^{\mathrm{a}}$ & CR $[27,33]$ \\
\hline 3 & 3.93 & 290 & $272,225,217,211,201,199,181,124,119$ & 3-hydroxylatifaliumin $\mathrm{C}^{\mathrm{b}}$ & TA [33] \\
\hline 4 & 4.97 & 276 & $258,219,215,201,189,175,153$ & Dihydro-latifaliuminC $^{a}$ & TA [33] \\
\hline 5 & 5.71 & 274 & $256,225,217,207,199,197,181$ & Latifaliumin $C^{a}$ & TA [33] \\
\hline 6 & 5.76 & 350 & $332,281,267,255,223,193,180$ & Unidentified & \\
\hline 7 & 6.54 & 334 & $316,298,270,267,255,238,173$ & $\begin{array}{l}2 \alpha-\text { Hydroxy-3-hydro-6-O- } \\
\text { methyloduline }^{\mathrm{b}}\end{array}$ & $\mathrm{HO}[36]$ \\
\hline 8 & 7.17 & 274 & $231,225,213,198,183$ & $\mathrm{~N}$-demethyl-galanthamine & GA $[26,27]$ \\
\hline 9 & 9.48 & 290 & $272,254,226,149,136,112,68$ & Dihydrolycorine & LY [29-31] \\
\hline 10 & 10.05 & 306 & $288,270,229,189$ & Crinamabine ${ }^{a}$ & CR [35] \\
\hline 11 & 12.90 & 288 & $270,252,222,177,147,119,95$ & Lycorine & LY $[1,17]$ \\
\hline 12 & 14.08 & 286 & $250,240,226,147$ & (+)-5,6-dehydrolycorine & LY [5] \\
\hline 13 & 14.79 & 290 & $272,233,215,189$ & lycoramine & GA [1] \\
\hline 14 & 17.40 & 288 & $270,231,225,213,198,181$ & Galanthamine & GA [17] \\
\hline 15 & 18.24 & 306 & $288,247,233,229,215,201,189$ & lycoramine N-oxide & GA $[15,25]$ \\
\hline 16 & 22.04 & 264 & $247,189,166,149,133,116$ & Hippadine & LY [32] \\
\hline 17 & 23.23 & 288 & $270,255,239,193,162,151,121,108,94$ & Pluviine & $\operatorname{LY}[16,19]$ \\
\hline 18 & 24.20 & 262 & $244,228,219,205,179,165,147,123,98,91$ & Unidentified & \\
\hline 19 & 26.58 & 302 & $284,266,255,193,175,145,108,94$ & Oduline & $\mathrm{HO}[36]$ \\
\hline 20 & 26.74 & 332 & $300,282,264,234,225,213,199,169$ & Ambelline ${ }^{a}$ & CR $[17,34]$ \\
\hline
\end{tabular}


Table 1. Cont.

\begin{tabular}{|c|c|c|c|c|c|}
\hline $\begin{array}{l}\text { Peak } \\
\text { No. }\end{array}$ & $\begin{array}{c}\mathbf{R}_{\mathrm{t}} \\
(\mathrm{min})\end{array}$ & $\begin{array}{c}\text { PI-MS } \\
{[\mathrm{M}+\mathrm{H}]^{+}}\end{array}$ & MS/MS Data & Identification & Alkaloid Type/Ref. \\
\hline 21 & 27.33 & 272 & $254,242,226,149,136,108$ & Vittatine & CR [17] \\
\hline 22 & 27.88 & 318 & $300,286,268,250,227,209,199,149$ & Crinamidine $^{a}$ & CR $[17,33]$ \\
\hline 23 & 29.08 & 332 & $300,282,275,267,255,243,223,195,124$ & Hippeastrine N-oxide & $\mathrm{HO}[37]$ \\
\hline 24 & 29.15 & 286 & $255,229,225,197,179,168,58$ & Narwedine ${ }^{a}$ & GA [28] \\
\hline 25 & 29.64 & 302 & $270,259,226,211,196,181,168$ & Haemanthamine & CR [17] \\
\hline 26 & 30.96 & 316 & $298,280,273,239,222,191,126,96,83$ & hippeastrine & $\mathrm{HO}[36]$ \\
\hline 27 & 31.86 & 332 & $314,282,253,239,211,223,175,96$ & \multirow{2}{*}{$\begin{array}{l}2 \alpha-\text { Hydroxy-6-O-methyloduline } \\
(+)-8,9-\text { methylenedioxylhomolycorine } \\
\text { N-oxide }\end{array}$} & $\mathrm{HO}[36]$ \\
\hline 28 & 32.82 & 316 & $298,280,267,239,207,191,176,160,108,94$ & & $\mathrm{HO}[5]$ \\
\hline 29 & 33.15 & 318 & $286,271,267,177$ & Unidentified & \\
\hline 30 & 33.38 & 332 & $300,282,257,251,243,191,163,94$ & 2-methoxyoduline ${ }^{b}$ & $\mathrm{HO}[36]$ \\
\hline 31 & 34.49 & 334 & $302,270,259,245,231,217,213,199$ & 3,11-dimethoxy-lycoramine ${ }^{b}$ & GA [17] \\
\hline 32 & 35.58 & 316 & $\begin{array}{c}285,267,256,239,228 \\
207,175,157,129,118\end{array}$ & Unidentified & \\
\hline 33 & 36.19 & 332 & $300,284,271,251,239,219,191,94,81$ & Unidentified & \\
\hline 34 & 36.19 & 266 & $250,236,222,208,109$ & Unidentified & \\
\hline 35 & 36.84 & 332 & $\begin{array}{l}314,300,282,271,264,240 \\
224,211,181,153,120,107\end{array}$ & Unidentified & \\
\hline 36 & 37.56 & 346 & $314,282,253,239,225,211,175,147,96$ & $2 \alpha$-Methoxy-6-O-methyloduline & $\mathrm{HO}[36]$ \\
\hline 37 & 40.20 & 344 & $312,280,266,252,195,89$ & Unidentified & \\
\hline 38 & 41.15 & 298 & $270,248,238,212,180$ & Unidentified & \\
\hline 39 & 44.57 & 346 & $288,241,239,211,209,183,168,140,116,94$ & Unidentified & \\
\hline
\end{tabular}

\subsubsection{Identification of Galanthamine Type Alkaloids}

For the identification of galanthamine type alkaloids, the loss of $\mathrm{N}$-methyl and vicinal carbon atoms was the typically characteristic fragmentation pathways in the MS analysis among AAs. According to the MS/MS spectra, seven peaks, numbered as 1, 8, 13, 14, 15, 24, and 31, were identified and classified into this group.

By comparing the MS/MS data with the authentic standard, peaks 13 and 14 were definitely identified as lycoramine and galanthamine, respectively [1,17]. For lycoramine (peak 13), several abundant fragment ions at $\mathrm{m} / z 272\left[\mathrm{M}+\mathrm{H}-\mathrm{H}_{2} \mathrm{O}^{+}, 233\left[\mathrm{M}+\mathrm{H}-\mathrm{C}_{3} \mathrm{H}_{7} \mathrm{~N}\right]^{+}\right.$, and 215 $\left[\mathrm{M}+\mathrm{H}-\mathrm{H}_{2} \mathrm{O}-\mathrm{C}_{3} \mathrm{H}_{7} \mathrm{~N}\right]^{+}$were observed, and another fragment ion at $m / z 189$ was attributed to the further loss $\mathrm{C}_{2} \mathrm{H}_{2}(26 \mathrm{Da}$ ) from fragment ion at $m / z 215$. For galanthamine (peak 14), the fragment ion at $m / z 270$ was formed by the neutral loss of $\mathrm{H}_{2} \mathrm{O}$. The further loss of the $\mathrm{N}$ vicinal moiety from fragment ion at $\mathrm{m} / z 270$ produced fragment ions at $\mathrm{m} / \mathrm{z} 231,225,213$ and 198 . The fragment ion at $m / z 181$ was observed due to the further neutral loss of $\mathrm{CH}_{3} \mathrm{OH}(32 \mathrm{Da})$ from ion at $m / z 213$.

Figure 3 showed the MS/MS spectrum and the fragmentation pathways of peak 31, in which several abundant fragments at $\mathrm{m} / z 231,213$ and 198 were found very similar to galanthamine. Since peak 31 showed a molecular ion at $m / z 334\left([\mathrm{M}+\mathrm{H}]^{+}\right)$and two subsequent fragment ions at $m / z 302\left(\left[\mathrm{M}+\mathrm{H}-\mathrm{CH}_{3} \mathrm{OH}\right]^{+}\right)$and at $m / z 270\left(\left[\mathrm{M}+\mathrm{H}-2 \mathrm{CH}_{3} \mathrm{OH}\right]^{+}\right)$, suggesting the presence of two methoxy groups, thus it can be tentatively identified as 3, 11-dimethoxy-lycoramine [17]. Similar to MS/MS of galanthamine, several typical fragment ions at $m / z 231,213$ and 198 were also observed for peak 8. Considering the molecular ion of peak 8 at $\mathrm{m} / z 274[\mathrm{M}+\mathrm{H}]^{+}\left(\mathrm{C}_{16} \mathrm{H}_{19} \mathrm{NO}_{3}\right)$, peak 8 was thus tentatively identified as $\mathrm{N}$-demethyl-galanthamine [26,27]. In this way, peak $\mathbf{1}$ could be tentatively identified as 1,11-didehydrogalanthamine, since its molecular ion at $m / z 284[\mathrm{M}+\mathrm{H}]^{+}\left(\mathrm{C}_{19} \mathrm{H}_{27} \mathrm{NO}_{4}\right)$, and similar fragment ions at $m / z 213$ and 198 to those of galanthamine were observed along with an abundant fragment ion at $m / z 266$ [17].

In addition, peak 15 was also tentatively identified as lycoramine $\mathrm{N}$-oxide based on the characteristic fragment ions at $m / z 233,215$ and 189 similar to galanthamine and its molecular ion observed at $m / z 306\left([\mathrm{M}+\mathrm{H}]^{+}\right)$, along with some weak fragment ions at $m / z 288$ and 247 by the successive loss of $\mathrm{H}_{2} \mathrm{O}(18 \mathrm{Da})$ and $\mathrm{C}_{3} \mathrm{H}_{3} \mathrm{~N}(53 \mathrm{Da})[15,25,26]$. As for peak 24, a neutral loss of $\mathrm{CH}_{3} \mathrm{NH}_{2}$ (31 Da) from the molecular ion at $m / z 286[\mathrm{M}+\mathrm{H}]^{+}$resulted in a fragment ion at $m / z 255$, and the fragment ions at $m / z 225,197$ and 179 could be attributed to the successive loss of $\mathrm{CH}_{2} \mathrm{O}, \mathrm{CO}$ and $\mathrm{H}_{2} \mathrm{O}$ from fragment ion at $m / z 255$. Another abundant fragment ion at $m / z 229\left[\mathrm{M}+\mathrm{H}-\mathrm{C}_{3} \mathrm{H}_{7} \mathrm{~N}\right]^{+}$ 


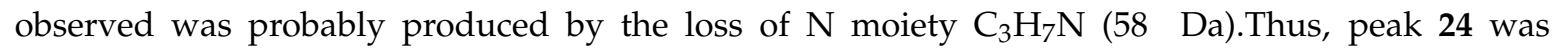
tentatively identified as narwedine [28].
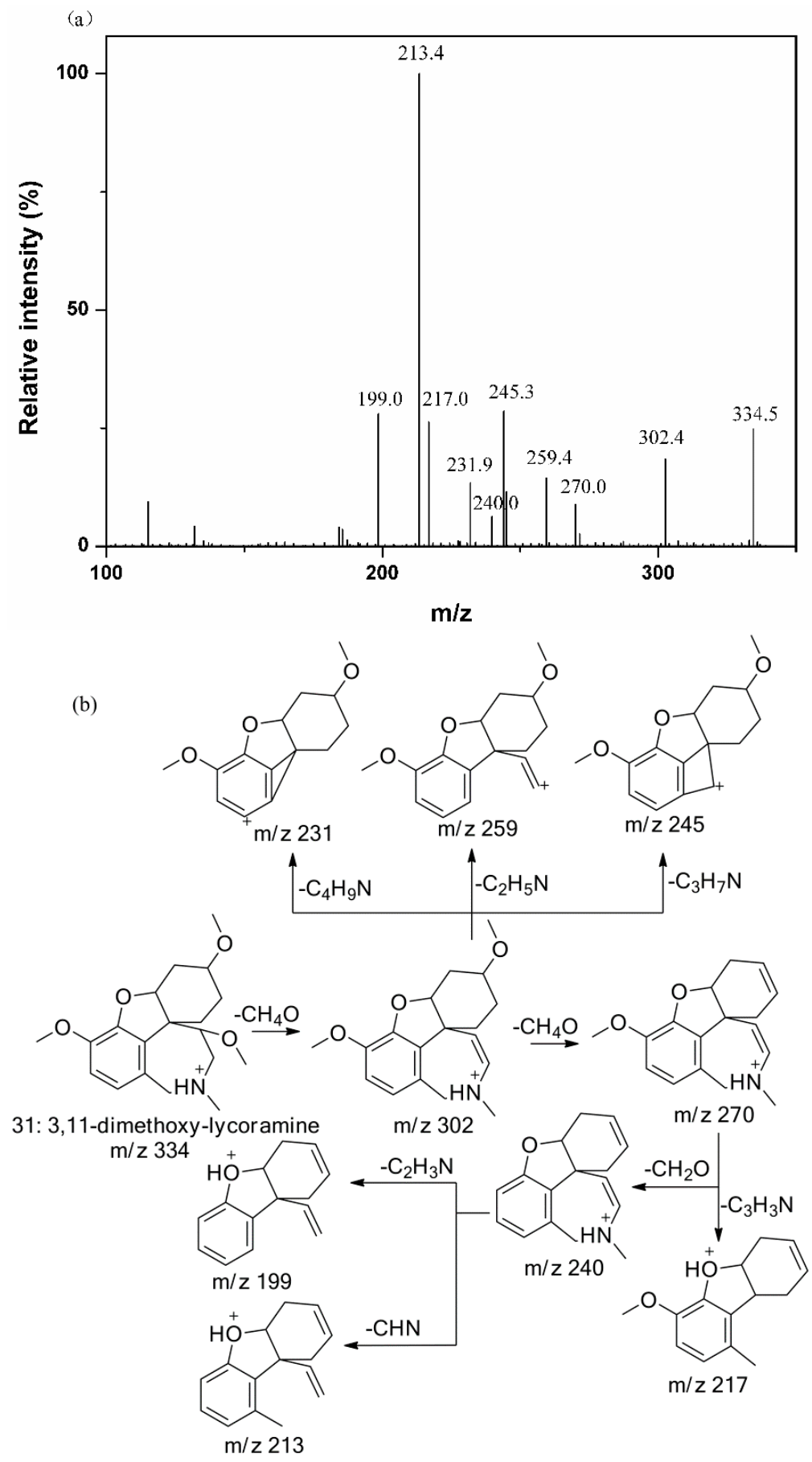

Figure 3. The MS/MS spectrum of peak 31 (a) and the proposed fragmentation pathways (b).

\subsubsection{Identification of Lycorine Type Alkaloids}

Through the investigation on fragment pathways of lycorine type alkaloids, the unique structures of this type typically produced characteristic fragment ions via Retro-Diels-Alder (RDA) cleavages. Based on their MS/MS data, peaks 9, 11, 12, 16, and 17 were identified and classified into lycorine type alkaloids. 
Among the lycorine type alkaloids identified, both peak $\mathbf{1 1}$ and peak 17 exhibited a $[\mathrm{M}+\mathrm{H}]^{+}$ion at $m / z$ 288. For peak 11, in addition to the RDA cleavages of $\mathrm{B}$ and $\mathrm{C}$ rings produced two characteristic fragment ions at $m / z 177\left[\mathrm{M}+\mathrm{H}-\mathrm{C}_{6} \mathrm{H}_{9} \mathrm{NO}\right]^{+}$and $147\left[\mathrm{M}+\mathrm{H}-\mathrm{C}_{7} \mathrm{H}_{11} \mathrm{NO}_{2}\right]^{+}$, the successive loss of $\mathrm{H}_{2} \mathrm{O}, 2 \mathrm{H}_{2} \mathrm{O}$ and $\mathrm{CH}_{2} \mathrm{O}$ from the parent ion at $\mathrm{m} / z 288$ yielded three fragment ions at $\mathrm{m} / \mathrm{z}$ 270, 252 and 222, respectively. In reference to the MS/MS data from the authentic standard [1,17], peak 11 was identified as lycorine. As for peak 17, the loss of $\mathrm{C}_{6} \mathrm{H}_{9} \mathrm{~N}$ (95) and $\mathrm{C}_{11} \mathrm{H}_{14} \mathrm{O}_{3}$ (194) from $[\mathrm{M}+\mathrm{H}]^{+}$led to the characteristic fragment ions at $m / z 193$ and 94 by RDA cleavages and the fragment ion at $m / z 270$ was observed due to the loss of $\mathrm{H}_{2} \mathrm{O}(18 \mathrm{Da})$. The further RDA cleavage of fragment at $m / z 270$ yielded two fragment ions at $m / z 255\left[\mathrm{M}+\mathrm{H}-\mathrm{H}_{2} \mathrm{O}-\mathrm{NH}\right]^{+}$and $m / z 239$ $\left[\mathrm{M}+\mathrm{H}-\mathrm{H}_{2} \mathrm{O}-\mathrm{CH}_{5} \mathrm{~N}\right]^{+}$. Thus, peak 17 was finally identified as pluviine $[16,29]$. In this way, peak 9 was also identified based on the typical fragment ions at $m / z 272,254$ and 149, which were $2 \mathrm{Da}$ more than those corresponding ions at $m / z$ 270, 252 and 147 for lycorine. Therefore, peak 9 was identified as dihydrolycorine [26,29-31]. For peak 12, the loss of $\mathrm{H}_{2} \mathrm{O}$ and $\mathrm{C}_{2} \mathrm{H}_{2} \mathrm{O}$ from the molecular ion at $m / z 286[\mathrm{M}+\mathrm{H}]^{+}$produced abundant fragment ions at $m / z 250\left[\mathrm{M}+\mathrm{H}-2 \mathrm{H}_{2} \mathrm{O}\right]^{+}$and 226 $\left[\mathrm{M}+\mathrm{H}-\mathrm{H}_{2} \mathrm{O}-\mathrm{C}_{2} \mathrm{H}_{2} \mathrm{O}\right]^{+}$by successive neutral losses. Meanwhile, the fragment ion at $\mathrm{m} / \mathrm{z} 147$ was also observed by the loss of $\mathrm{C}_{7} \mathrm{H}_{7} \mathrm{NO}$ (121 Da) due to RDA cleavages. Thus, peak 12 was tentatively identified as (+)-5,6-dehydrolycorine [5]. In respect to peak 16, several abundant fragment ions at $m / z$ 247, 149 and 166 were produced mainly via RDA cleavages. As a result, it was tentatively identified as (+)-5,6-dehydrolycorine based on the fragment pathways above [32].

\subsubsection{Identification of Crinine Type Alkaloids}

In terms of MS fragmentation pathways of crinine type alkaloids, the abundant fragment ions observed in the MS/MS spectrum were produced due to both RDA and $\alpha$-cleavages. As shown in Table 1, peaks 2, 10, 20, 21, 22 and 25 were classified into crinine type group based on their characteristic fragment ions.

Compared the MS/MS data with those from authentic standards, peak 21 and 25 were identified as vittatine and haemanthamine [17]. For peak 21, except for the most intensive and characteristic fragmention at $m / z 136$ produced due to the RDA and $\alpha$-cleavages, the fragment ions at $m / z 254$, 240 , and 226 were observed by successive neutral losses from the molecular ion at $m / z 272[\mathrm{M}+\mathrm{H}]^{+}$. As for peak 25, the characteristic fragment ion at $m / z 259[\mathrm{M}+\mathrm{H}-43]^{+}$was produced by RDA and $\alpha$-cleavages, and the fragment ion at $m / z 226$ was observed due to the neutral loss of $\mathrm{CH}_{3} \mathrm{OH}$ and further dissociation of an $\mathrm{H}$ radical from the fragment ion at $m / z 259$. Fragment ions at $m / z 270,252$, 211 and 181 were generated by the successive neutral loss of $\mathrm{CH}_{3} \mathrm{OH}(32 \mathrm{Da}), \mathrm{H}_{2} \mathrm{O}(18 \mathrm{Da})$, as well as RDA cleavage radical eliminating $\mathrm{C}_{2} \mathrm{H}_{3} \mathrm{~N}(41 \mathrm{Da})$ and $\mathrm{CH}_{2} \mathrm{O}(30 \mathrm{Da})$ from the molecular ion at $\mathrm{m} / \mathrm{z}$ $302[\mathrm{M}+\mathrm{H}]^{+}$.

In regards to peaks 2 and 22, the similar fragment ions at 286, 268, 250 and 227 were observed. Peak 2 showed a molecular ion at $m / z 304[\mathrm{M}+\mathrm{H}]^{+}$, and a differential fragment ion at $m / z 150$ was probably generated by the loss of $\mathrm{C}_{7} \mathrm{H}_{2} \mathrm{O}_{2}$ from the fragment ion at $m / z 268$. For peak 22, the loss of $\mathrm{H}_{2} \mathrm{O}$ from the molecular ion $[\mathrm{M}+\mathrm{H}]^{+}$at $m / z 318$ produced the fragment ion at $m / z 300$, and then a further loss of $\mathrm{H}_{2} \mathrm{O}$ and $\mathrm{CO}$ from fragment ion at $m / z 227$ resulted in the fragment ions at $m / z 209$ and 199, respectively. Based on interpretations of these fragment ions above, peaks 2 and 22 could be tentatively identified as 11-hydroxyvittatine $\mathrm{N}$-oxide and crinamidine, respectively $[17,27,33]$. With the molecular ion at $m / z 332\left([\mathrm{M}+\mathrm{H}]^{+}\right)$, peak 20 exhibited the similar MS/MS spectrum as that of peak 22 and was identified as ambelline [3,17]. As for peak 10, with the molecular ion at $\mathrm{m} / \mathrm{z}$ $306\left([\mathrm{M}+\mathrm{H}]^{+}\right)$, its four major fragment ions at $m / z 288,270,229$ and 152 were 2 Da more than those corresponding fragment ions at $m / z 286,268,227$ and 150 from peak 2, respectively, along with another two differential fragment ions at $m / z 215$ and 189 probably produced due to the cleavage of $B$ ring. Based on these MS/MS data, peak 10 was identified as crinamabine which was reported from other plants in the past [34]. 


\subsubsection{Identification of Homolycorine Type Alkaloids}

As for MS/MS data derived from homolycorine type alkaloids, major fragment ions were observed due to RDA cleavage and the losses of some substituents. Peaks 7, 19, 23, 26, 27, 28, 30 and 36 were classified into homolycorine type group and identified based on their MS/MS data.

The MS/MS spectrum of peak 7 with the $[\mathrm{M}+\mathrm{H}]^{+}$ion at $m / z 334$ was shown in Figure 4a, and it could be tentatively identified as $2 \alpha$-Hydroxy-3-hydro-6-O-methyloduline [35] based on the proposed fragment pathways in Figure $4 b$.

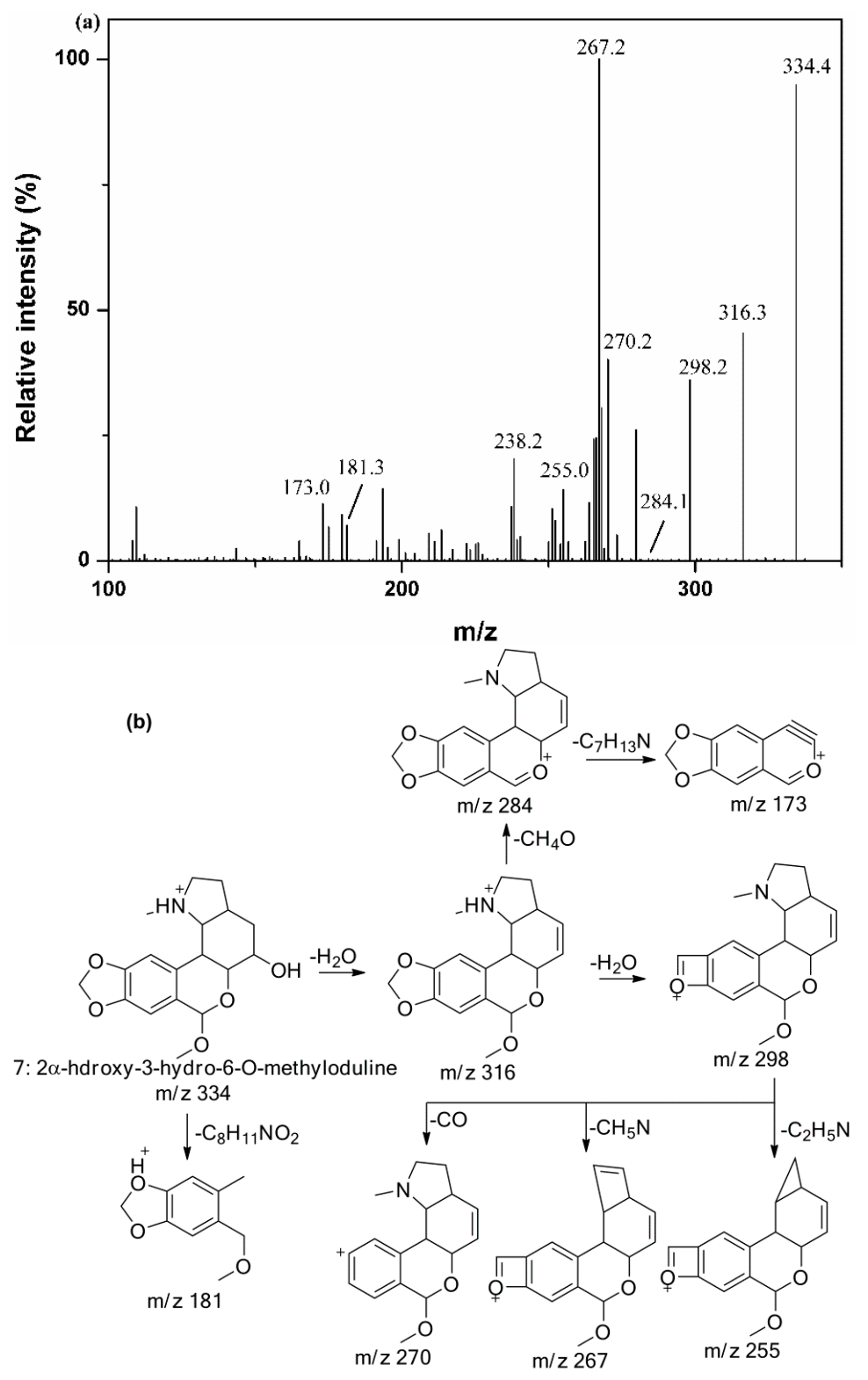

Figure 4. The MS/MS spectrum of peak 7 (a) and the proposed fragmentation pathways (b).

Peaks 19, 26, 27 and 36, which showed the corresponding $[\mathrm{M}+\mathrm{H}]^{+}$ions at $m / z 302,316,332$ and 346 , respectively, were identified as oduline, hippeastrine and $2 \alpha$-Hydroxy-6-O-methyloduline, $2 \alpha$-Methoxy-6-O-methyloduline by comparing their MS/MS spectra with those reported standards [35]. In the MS/MS spectrum of peak 23, fragment ions at $m / z 275,267,255,243$ and 223 were produced mainly due to the loss of $\mathrm{N}$ vicinal moiety, the fragment ion at $m / z 195$ was observed because of the further loss of $\mathrm{CO}$ from the fragment ion at $m / z 223$, and another fragment 
ion at $m / z 124$ was produced by RDA cleavage. Thus, peak 23 was identified as hippeastrine N-oxide [36].

In regard to peak 28, the abundant fragment ion at $m / z 207$ was produced by RDA cleavage from its $[\mathrm{M}+\mathrm{H}]^{+}$ion at $m / z$ 316. Comparing the MS/MS data with those of peak 26, the fragment ion at $\mathrm{m} / \mathrm{z} 126$ was not observed, suggesting the lack of a hydroxyl at C-2. Thus, peak $\mathbf{2 8}$ was tentatively identified as (+)-8,9-methylenedioxyl-homolycorine N-oxide [5]. For peak 30, the fragment ion at $m / z 300$ corresponding to the loss of methyl group from its parent ion at $m / z 316[\mathrm{M}+\mathrm{H}]^{+}$, and another fragment ion at $m / z 191$ was observed due to the loss of $\mathrm{C}_{8} \mathrm{H}_{15} \mathrm{NO}$ (141 Da) produced by RDA cleavage. Therefore, peak 30 was tentatively identified as 2-methoxyoduline [35].

\subsubsection{Identification of Tazettine Type Alkaloids}

According to their MS/MS data and the proposed fragmentation patterns, peaks 3, 4 and 5 could be classified as tazettine type alkaloids. The MS/MS spectrum and the proposed fragment pathway of peak 5 were shown in Figure 5. In the MS/MS spectra of peak $\mathbf{3}$ and $\mathbf{5}$, the same series of fragment ions at $m / z 225,217,199$ and 181 were detected, and the neutral losses of $\mathrm{H}_{2} \mathrm{O}$ from the corresponding $[\mathrm{M}+\mathrm{H}]^{+}$ions at $m / z 290$ and 274 produced fragment ions at $m / z 272$ for peak 3 and $m / z 256$ for peak 5, respectively. By comparing their MS/MS spectra with those of the authentic standards reported, peak $\mathbf{3}$ was identified as 3-hydroxylatifaliumin C, while peak $\mathbf{5}$ was identified as Latifaliumin C [33]. For peak 4, the major fragment ions at $m / z 258,219,201$ and 173 were 2 Da more than those corresponding fragment ions at $m / z 256,217,199$ and 171 of peak 5 . In addition, the molecular ion at $m / z 276$ of peak 4 also showed 2 Da more than that of peak 5 and was tentatively identified as dihydro-latifaliumin C [33].

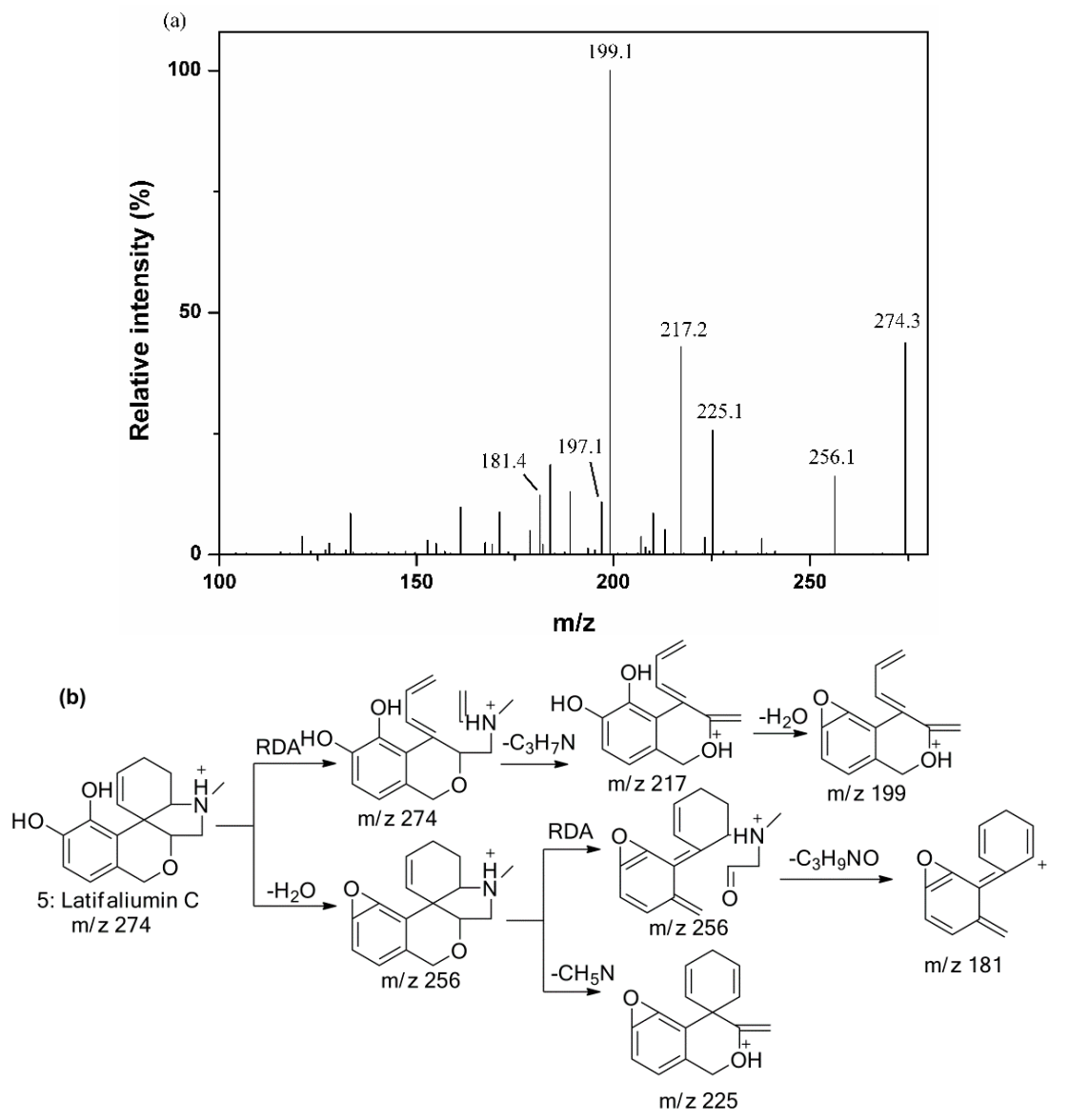

Figure 5. The MS/MS spectrum of peak 5 (a) and the proposed fragmentation pathways (b). 


\subsection{Comparison of AAs among the Three Lycoris Species}

Based on the identification of AAs from the three Lycoris species above, a comparison of AAs among different species was conducted, which was depicted in Figure 6a. It can be summarized that 19 alkaloids were found in the sample of L. aurea, while 28 and 18 in L. radiata and L. guangxiensis, respectively. Of these, nine AAs (peaks numbered with 4, 8, 11, 13, 14, 17, 19, 21 and 22) are the common components existing in all three species, and some components were found only in two of them, which are four AAs (peaks numbered as 2, 15, 25, and 26) in L. radiata and L. aurea, two AAs (peaks numbered as 3 and 10) in L. radiata and L. guangxiensis, and two AAs (peaks numbered as 9 and 24) in L. aurea and L. guangxiensis, respectively. To find potential AAs markers for the identification or quality control of different species from genus Lycoris, unique peaks of these three species were successfully picked out, which are four AAs (peaks numbered with 5, 33, 37, and 38) in L. aurea, 14 AAs (peaks numbered as 1, 6, 7, 12, 20, 23, 27, 28, 29, 30, 32, 34, 35, and 39) in L. radiata, and four AAs (peaks numbered as 16, 18, 31, and 36) in guangxiensis, respectively. Briefly, the crosscutting and inclusion relationships of AAs found in these three Lycoris species can provide great knowledge on both quality control for these species and better understanding of the correlation between AAs and their associated activities.
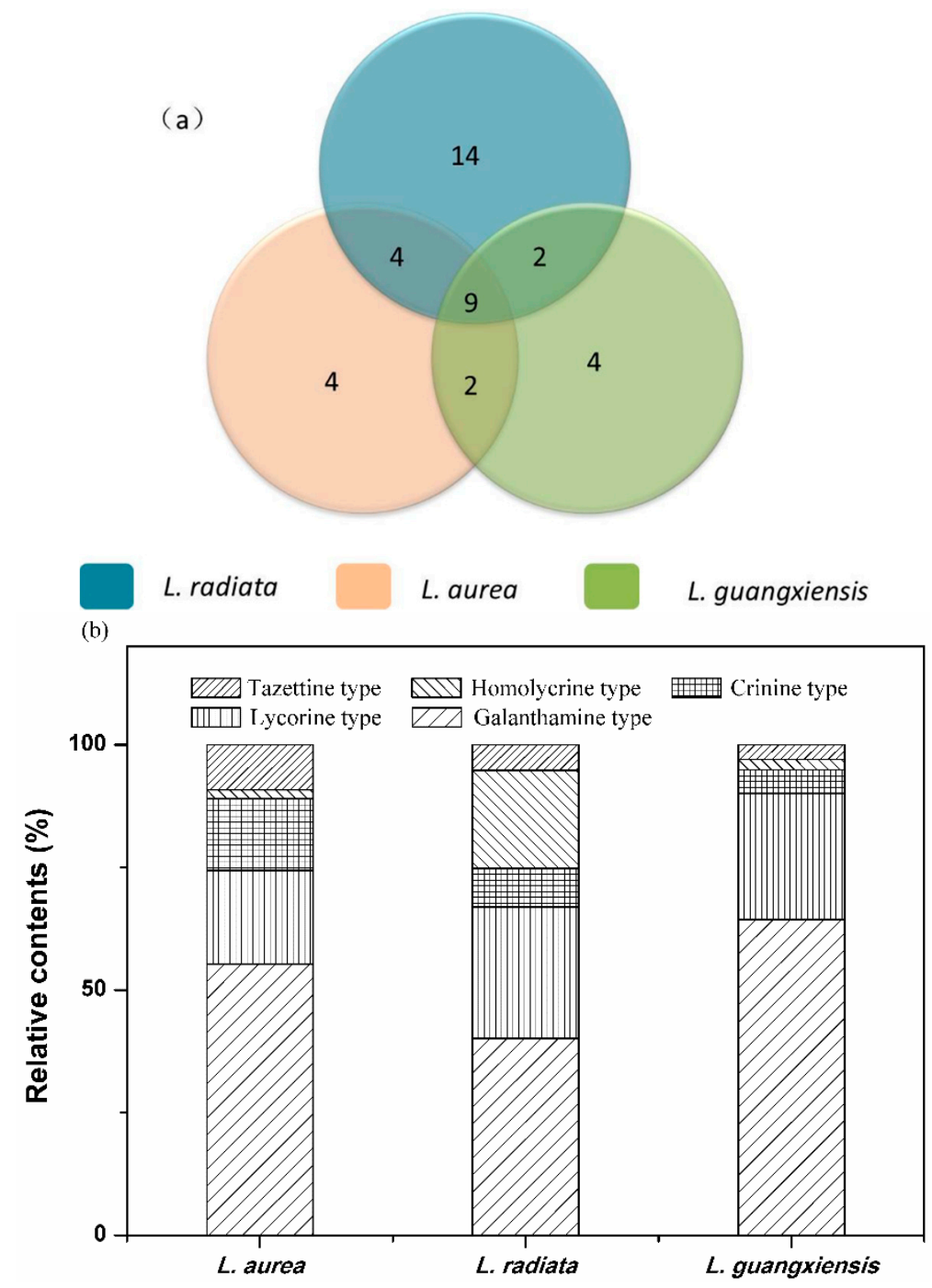

Figure 6. The number of AAs (a) and relative contents of five types of AAs (b) detected from L. radiata, L. aurea and L. guangxiensis. 
Since the evaluation of bioactivity of AAs in one plant species depends on both the qualitative and quantitative knowledge, the quantitative information of the five types of AAs in the three Lycoris species was then investigated based on their LC chromatograms, which was shown in Figure 6b. It can be seen that galanthamine and lycorine type alkaloids were the two major types of AAs accounting for $55.3 \%$ and $19.1 \%$ of galanthamine and lycorine type in L. aurea, $40.1 \%$ and $26.9 \%$ of galanthamine and lycorine type in L. radiate and $64.4 \%$ and $25.6 \%$ of galanthamine and lycorine type in L. guangxiensis, respectively. However, the discrepancies were mainly found in the contents of the other three types among the three species. In L. aurea, those three types account for about $25.6 \%$ from the total AAs, which are $1.8 \%, 14.6 \%$, and $9.2 \%$ for homolylcorine, crinine, and tazettine types of alkaloids, respectively. In $L$. radiata, the homolylcorine type is another remarkable type making up $20.0 \%$, which is next to the lycorine type, followed by the crinine type with $7.8 \%$ and tazettine with $5.2 \%$, respectively. While in L. guangxiensis, the remainig three types together account for only $10.0 \%$ of the total AAs, in which $4.9 \%$ constitutes the crinine type, followed by $3.0 \%$ for the tazettine type and $2.1 \%$ for the homolylcorine type, respectively.

\subsection{Comparison of Anti-HepG2 Activity of AAs in the Three Lycoris Species}

AAs were the major anti-tumor compounds from genus Lycoris plants. Undoubtedly, the discrepancies of AAs composition and contents in different Lycoris species will result in differences in their bioactivity. Therefore, a comparison of the anti-HepG2 activity of the total AAs extracted from the three Lycoris species was conducted, in which CCK-8 (Cell Counting Kit-8) was employed. The result is shown in Figure 7. It was observed that the three species showed different inhibitory rates of HepG2 at $78.02 \%, 84.91 \%$ and $66.81 \%$ for L. aurea, L. radiate and L. guangxiensis, respectively, indicating that there exist differences in bioactivity of AAs from the three species. However, the structural subgroups and anti-cancer investigation indicated that homolycorine type (nobilisitine $\mathrm{B}$ and clivonine) and tazettine type (tazettine) AAs displayed no notable activity, while some of the lycorine and crinine type AAs showed significant cytostatic effects on actin cytoskeleton rigidity [37]. Nevertheless, pretazettine belonging to the tazettine type was reported to inhibit the growth of Hela cells [12]. (+)-8-hydroxy-homolycorine- $\alpha$-N-oxide belonging to homolycorine type exhibited significant cytotoxicity against the tested seven tumor cell lines [38]. Considering the multi-component AAs and their distinct bio-activities, the anti-HepG2 activities could be attributed to the synergistic effects of the samples tested.

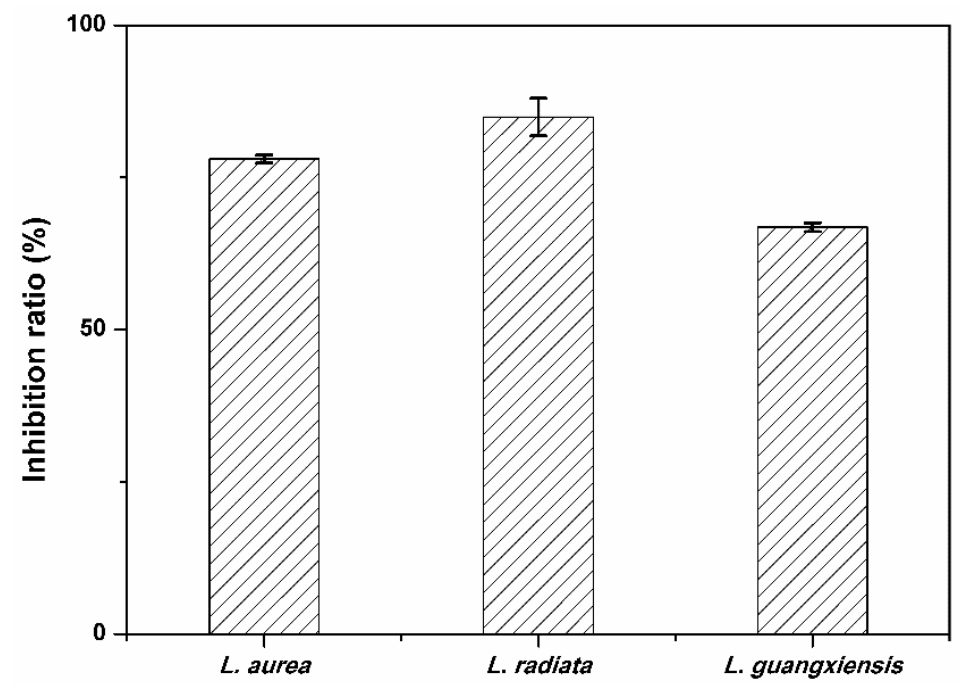

Figure 7. The anti-HepG2 activity of AAs from L. aurea, L. radiata and L. guangxiensis. (The error bars indicated RSDs calculated from triplicate tests). 
To determine the potential of anti-HepG2 activities of different types of AAs, a preliminary investigation into the correlations between the inhibitory rates and the content of AAs among the three Lycoris species was conducted. It can be observed from Figure $6 \mathrm{~b}$ that the two remarkable types of AAs, i.e., galanthamine and lycorine type alkaloids, may result in the general anti-HepG2 activity, with inhibitory rates ranging from $66.81 \%-84.91 \%$ among the three species. The highest inhibitory rate (i.e., $84.91 \%$ ) observed from $L$. radiata can be attributed to its remarkable content of homolylcorine type alkaloids which were found to be much lower in the other two species. Thus, in this study, galanthamine, lycorine, and homolylcorine type alkaloids were proposed as the most promising anti-HepG2 AAs from the Lycoris species. This may contribute to the further identification of the anti-tumor components in the AAs from Lycoris species in the future.

\section{Experimental Section}

\subsection{Chemicals}

Formic acid, ammonium acetate (AA) and acetonitrile (ACN) of HPLC grade were purchased from ROE Scientific INC, ANROUR Chemicals Supply, and Fisher Scientific, respectively. Oasis MCX cartridges $(500 \mathrm{mg} / 3 \mathrm{~mL})$ used for sample preparation were purchased from Weltch CO. (Wuhan, China). Methanol, Ethanol, Chloroform, Hydrochloric acid ( $\mathrm{HCl})$, Petroleum ether (PE), ammonia, and acetone were all of analytical grade and purchased from Sino-pharm chemical Reagent CO. Water for HPLC and LC-MS was prepared with EPED (Nanjing Yeap Esselte Technology Development Co., Nanjing, China).

\subsection{Plant Materials and Sample Preparation}

Identified to be Lycoris radiata (L. radiata), Lycoris aurea (L. aurea) and Lycoris guangxiensis (L. guangxiensis), fresh lycoris materials of three species were collected from Wuhan botanical garden in April 2014. The bulbs of lycoris were cut into slices and dried in the oven below $30^{\circ} \mathrm{C}$. The dry slices were weighed, and ultrasonically extracted with $90 \%$ ethanol for $30 \mathrm{~min}$. After repeated extraction three times, the extracts were combined and filtered, then the supernatants were evaporated under reduced pressure to afford syrup residues. The resulted residues were dispersed in $5 \% \mathrm{HCl}$, and extracted with petrol ether (PE) to remove chlorophyll. The $\mathrm{pH}$ value of water phase was adjusted to 9.5 with ammonia solution, and further extracted repeatedly with chloroform. The chloroform phase was combined and concentrated to yield crude AAs. An aliquot of crude AAs solutions was further enriched with Oasis MCX (500 mL/3 mL) cartridges in the following steps: firstly, the cartridges were activated with methanol $(3 \mathrm{~mL})$ and methanol-water $(85: 15,3 \mathrm{~mL})$; secondly, samples dissolved in methanol with $1 \%$ formic acid solution were loaded to the cartridges, and methanol was used as wash solution; thirdly, the AAs for analysis were eluted with $3 \mathrm{~mL}$ of $5 \%$ ammonia in acetone. At last, the eluents were collected and dried with Pressure Blowing Concentrator. The residues were dissolved with $5 \%$ methanol, filtered with 0.22 micro-filter membrane and stored at $4{ }^{\circ} \mathrm{C}$ before HPLC-UV and LC-MS analysis.

\subsection{HPLC-UV/ESI-MS/MS Analysis}

\subsubsection{HPLC-UV Conditions}

A Thermo Accela 1250 HPLC consisting of an auto-sampler coupled with a UV-visible detector (Thermo Fisher Scientific, San Jose, CA, USA) was employed for the analysis of AAs. A $10 \mu \mathrm{L}$ aliquot of AAs solution was injected and analyzed on a Phenomenex ODS column $(150 \times 2.00 \mathrm{~mm}$, $5 \mu \mathrm{m}$, Phenomenex). The column temperature was set at $30^{\circ} \mathrm{C}$, and the flow rate was $0.2 \mathrm{~mL} / \mathrm{min}$. The mobile phase $\mathrm{A}$ and $\mathrm{B}$ were $40 \mathrm{mM}$ ammonium acetate aqueous solution and acetonitrile, respectively. The gradient was set as follows: $0-15 \mathrm{~min}, 5 \%$ (B); $15-17 \mathrm{~min}, 5 \%-10 \%$ (B); $17-20 \mathrm{~min}$, 
$10 \%$ (B); $20-30 \mathrm{~min}, 10 \%-18 \%$ (B); $30-55 \mathrm{~min}, 18 \%-68 \%$ (B). The chromatogram was recorded at a wavelength of $232 \mathrm{~nm}$.

\subsubsection{ESI-MS/MS Conditions}

For the ESI-MS/MS experiment, a Thermo Accela 600 HPLC system with a UV detector coupled to a TSQ Quantum Access MAX mass spectrometer (Thermo Fisher Scientific, San Jose, CA, USA) was used for the LC-MS analysis in the positive mode. MS conditions were set as follows: mass range from 200-1000 Da; Spray Voltage, $3.0 \mathrm{kV}$; Capillary temperature, $250^{\circ} \mathrm{C}$; Sheath gas pressure, $40 \mathrm{psi}$; Aux gar pressure, 10 psi.

\subsection{Quantitative Analysis of AAs}

The relative contents of AAs were calculated based on the peak areas from the LC chromatography, and the identification of the corresponding LC peaks was conducted by LC-MS/MS and compared with references or some standard AAs.

\subsection{Anti-HepG2 Activity Test}

The anti-HepG2 activity of the crude extracts was tested using human hepatic carcinoma cell line (HepG2, from CCTCC (China Center for Type Culture Collection)) with Cell Counting Kit-8 (CCK-8). Cells were cultured in a 96-well plate at a density of 5000 cells per well in DMEM (Dulbecco's Modified Eagle Medium) supplemented with 10\% fetal bovine serum (FBS). After cultured under $5 \% \mathrm{CO}_{2}$ at $37{ }^{\circ} \mathrm{C}$ for $24 \mathrm{~h}$, the cells were treated with AAs at the concentrations of $10 \mu \mathrm{g} / \mathrm{mL}$ in 3 duplicates. DMSO was used as control. After incubation for $48 \mathrm{~h}, 10 \mu \mathrm{L}$ of CCK-8 was added to each well. Another $2 \mathrm{~h}$ later, the optical density (OD) values were determined at $450 \mathrm{~nm}$ by microliter plate reader (MIOS Junior, Merck, Hercules, CA, USA). The inhibitory rate (\%) equals to $(\mathrm{ODC}-\mathrm{ODT}) / \mathrm{ODC} \times 100 \%[39,40]$, here, ODT and ODC were the OD values of blank control and alkaloids extracts, respectively.

\section{Conclusions}

In this study, an HPLC-UV/ESI-MS/MS method was employed to analyze and compare the fingerprint profiles of AAs from L. aurea, L. radiata and L. guangxiensis. As a result, 39 peaks corresponding to AAs were detected and 29 of them were identified by comparing their LC-MS/MS spectra with the corresponding standards reported. Twelve peaks of the identified AAs were firstly observed in Lycoris genus, of which five peaks belonged to the Amaryllidaceae family. To distinguish lycoris species from other plants rich in AAs, peaks 11, 13 and 14 corresponding to lycorine, lycoramine and galanthamine together could be selected as the marker of genus Lycoris in the Amaryllidaceae family. For these three species, peaks 5, 7 and 31 corresponding to Latifaliumin C in L. aurea, $2 \alpha$-Hydroxy-3-hydro-6-O-methyloduline in L. radiata and 3,11-dimethoxy-lycoramine in L. guangxiensis were the unique peaks which could be selected as the AAs marker for these three species, respectively. It is further revealed for the first time that the three species under investigation were different not only in the types of AAs, but also in their contents, and both contributed to their pharmacological distinctions. To the best of our knowledge, the current research provides the most detailed phytochemical profiles of AAs in these species, and offers valuable information for future valuation and exploitation of these medicinal plants.

Acknowledgments: This work was jointly supported by "the Hundred Talents Program" from Chinese Academy of Sciences (Grant No. 29Y429291a0129 to M. Guo), and the Sino-Africa joint research project (Grant No. SAJC201328 to M. Guo). Both funders played no roles in the study design, data collection and analysis, and decision to publish.

Author Contributions: Y.T. performed the experiments, and analyzed the data. Y.T. and C.Z. drafted the manuscript. M.G. conceived the study, participated in its design and coordination, and helped to draft the manuscript. All the authors read and approved the final manuscript. 
Conflicts of Interest: The authors declare no conflict of interest.

\section{References}

1. Zhou, X.; Liu, Y.B.; Huang, S.; Liu, Y. An LC-MS/MS method for the simultaneous determination of lycorine and galanthamine in rat plasma and its application to pharmacokinetic study of Lycoris radiata extract in rats. J. Huazhong Univ. Sci. Technol. Med. 2014, 34, 861-868. [CrossRef] [PubMed]

2. Nair, J.J.; van Staden, J. Pharmacological and toxicological insights to the South African Amaryllidaceae. Food Chem. Toxicol. 2013, 62, 262-275. [CrossRef] [PubMed]

3. Song, J.H.; Zhang, L.; Song, Y. Alkaloids from Lycoris aurea and their cytotoxicities against the head and neck squamous cell carcinoma. Fitoterapia 2014, 95, 121-126. [CrossRef] [PubMed]

4. Wang, D.; Gao, C.Y.; Liu, S.L.; Wei, L.X. Structure investigation of a new alkaloid from Zanthoxylum schinifolium Siebet zucc. Chem. Res. Chin. Univ. 1991, 7, 124-128.

5. Hao, B.; Shen, S.F.; Zhao, Q.J. Cytotoxic and antimalarial Amaryllidaceae alkaloids from the bulbs of Lycoris radiata. Molecules 2013, 18, 2458-2468. [CrossRef] [PubMed]

6. Cao, P.; Pan, D.S.; Han, S.; Yu, C.Y.; Zhao, Q.J.; Song, Y.; Liang, Y. Alkaloids from Lycoris caldwellii and their particular cytotoxicities against the astrocytoma and glioma cell lines. Arch. Pharm. Res. 2013, 36, 927-932. [CrossRef] [PubMed]

7. Atanasova, M.; Stavrakov, G.; Philipova, I.; Zheleva, D.; Yordanov, N.; Doytchinova, I. Galantamine derivatives with indole moiety: Docking, design, synthesis and acetylcholinesterase inhibitory activity. Bioorg. Med. Chem. 2015, 23, 5382-5389. [CrossRef] [PubMed]

8. Liu, J.; Hu, W.X.; He, L.F.; Ye, M.; Li, Y. Eeffectes of lycorine on HL-60 cells via arresting cell cycle and inducing apoptosis. FEBS Lett. 2004, 578, 245-250. [CrossRef] [PubMed]

9. Ingrassia, L.; Lefranc, F.; Mathieu, V.; Darro, F.; Kiss, R. Amaryllidaceae isocarbostyril alkaloids and their derivatives as promising antitumor agents. Transl. Oncol. 2008, 1, 1-13. [CrossRef] [PubMed]

10. Kornienko, A.; Evidente, A. Chemistry, biology, and medicinal potential of narciclasine and its congeners. Chem. Rev. 2008, 108, 1982-2014. [CrossRef] [PubMed]

11. Lamoral-Theys, D.; Andolfi, A.; van Goietsenoven, G.; Cimmino, A.; le Calve, B.; Wauthoz, N.; Megalizzi, V.; Gras, T.; Bruyere, C.; Dubois, J.; et al. Lycorine, the main phenanthridine Amaryllidaceae alkaloid, exhibits significant antitumor activity in cancer cells that display resistance to proapoptotic stimuli: An investigation of structure-activity relationship and mechanistic insight. J. Med. Chem. 2009, 52, 6244-6256. [CrossRef] [PubMed]

12. Van Goietsenoven, G.; Mathieu, V.; Lefranc, F.; Kornienko, A.; Evidente, A.; Kiss, R. Narciclasine as well as other Amaryllidaceae isocarbostyrils are promising GTP-ase targeting agents against brain cancers. Med. Res. Rev. 2013, 33, 439-455. [CrossRef] [PubMed]

13. Lefranc, F.; Sauvage, S.; van Goietsenoven, G.; Megalizzi, V.; Lamoral-Theys, D.; Debeir, O.; Spiegl-Kreinecker, S.; Berger, W.; Mathieu, V.; Decaestecker, C.; et al. Narciclasine, a plant growth modulator, activates rho and stress fibers in glioblastoma cells. Mol. Cancer Ther. 2009, 8, 1739-1750. [CrossRef] [PubMed]

14. Van Goietsenoven, G.; Hutton, J.; Becker, J.P.; Lallemand, B.; Robert, F.; Lefranc, F.; Pirker, C.; Vandenbussche, G.; van Antwerpen, P.; Evidente, A.; et al. Targeting of Eff1A with Amaryllidaceae isocarbostyrils as a strategy to combat melanomas. FASEB J. 2010, 24, 4575-4584. [CrossRef] [PubMed]

15. Giordani, R.B.; de Andrade, J.P.; Verli, H.; Dutilh, J.H.; Henriques, A.T.; Berkov, S.; Bastida, J.; Zuanazzi, J.A. Alkaloids from Hippeastrum morelianum Lem. (Amaryllidaceae). Magn. Reson. Chem. 2011, 49, 668-672. [CrossRef] [PubMed]

16. Wu, W.M.; Zhu, Y.Y.; Li, H.R.; Yu, H.Y.; Zhang, P.; Pi, H.F.; Ruan, H.L. Two new alkaloids from the bulbs of Lycoris sprengeri. J. Asian Nat. Prod. Res. 2014, 16, 192-199. [CrossRef] [PubMed]

17. Katoch, D.; Kumar, S.; Kumar, N.; Singh, B. Simultaneous quantification of Amaryllidaceae alkaloids from Zephyranthes grandiflora by UPLC-DAD/ESI-MS/MS. J. Pharm. Biomed. Anal. 2012, 71, 187-192. [CrossRef] [PubMed]

18. De Andrade, J.P.; Pigni, N.B.; Torras-Claveria, L.; Berkov, S.; Codina, C.; Viladomat, F.; Bastida, J. Bioactive alkaloid extracts from Narcissus broussonetii: Mass spectral studies. J. Pharm. Biomed. Anal. 2012, 70, 13-25. [CrossRef] [PubMed] 
19. Bozkurt-Sarikaya, B.; Kaya, G.; Onur, M.; Bastida, J.; Berkov, S.; Unver-Somer, N. GC/MS analysis of Amaryllidaceae alkaloids in Galanthus gracilis. Chem. Nat. Compd. 2014, 50, 573-575. [CrossRef]

20. Berkov, S.; Bastida, J.; Viladomat, F.; Codina, C. Analysis of galanthamine-type alkaloids by capillary gas chromatography-mass spectrometry in plants. Phytochem. Anal. 2008, 19, 285-293. [CrossRef] [PubMed]

21. Mroczek, T. Highly efficient, selective and sensitive molecular screening of acetylcholinesterase inhibitors of natural origin by solid-phase extraction-liquid chromatography/electrospray ionisation-octopole-orthogonal acceleration time-of-flight-mass spectrometry and novel thin-layer chromatography-based bioautography. J. Chromatogr. A 2009, 1216, 2519-2528. [PubMed]

22. Zhang, Y.; Chen, Z. Nonaqueous CE ESI-IT-MS analysis of Amaryllidaceae alkaloids. J. Sep. Sci. 2013, 36, 1078-1084. [CrossRef] [PubMed]

23. Berkov, S.; Viladomat, F.; Codina, C.; Suarez, S.; Ravelo, A.; Bastida, J. GC-MS of Amaryllidaceous galanthamine-type alkaloids. J. Mass Spectrom. 2012, 47, 1065-1073. [CrossRef] [PubMed]

24. Huang, S.D.; Zhang, Y.; He, H.P.; Li, S.F.; Tang, G.H.; Chen, D.Z.; Cao, M.M.; Di, Y.T.; Hao, X.J. A new Amaryllidaceae alkaloid from the bulbs of Lycoris radiata. Chin. J. Nat. Med. 2013, 11, 406-410. [CrossRef] [PubMed]

25. Pi, H.F.; Zhang, P.; Ruan, H.L.; Zhang, Y.H.; Sun, H.D.; Wu, J.Z. A new alkaloid from Lycoris aurea. Chin. Chem. Lett. 2009, 20, 1319-1320. [CrossRef]

26. Yang, Y.; Huang, S.X.; Zhao, Y.M.; Zhao, Q.S.; Sun, H.D. Alkaloids from the bulbs of Lycoris aurea. Helv. Chim. Acta 2005, 88, 2550-2553. [CrossRef]

27. Elgorashi, E.E.; Malan, S.F.; Stafford, G.I.; van Staden, J. Quantitative structure-activity relationship studies on acetylcholinesterase enzyme inhibitory effects of Amaryllidaceae alkaloids. S. Afr. J. Bot. 2006, 72, 224-231. [CrossRef]

28. De Andrade, J.P.; Guo, Y.; Font-Bardia, M.; Calvet, T.; Dutilh, J.; Viladomat, F.; Codina, C.; Nair, J.J.; Zuanazzi, J.A.; Bastida, J. Crinine-type alkaloids from Hippeastrum aulicum and H. Calyptratum. Phytochemistry 2014, 103, 188-195. [CrossRef] [PubMed]

29. Li, X.; Yu, H.Y.; Wang, Z.Y.; Pi, H.F.; Zhang, P.; Ruan, H.L. Neuroprotective compounds from the bulbs of Lycoris radiata. Fitoterapia 2013, 88C, 82-90. [CrossRef] [PubMed]

30. He, J.; Qi, W.B.; Wang, L.; Tian, J.; Jiao, P.R.; Liu, G.Q.; Ye, W.C.; Liao, M. Amaryllidaceae alkaloids inhibit nuclear-to-cytoplasmic export of ribonucleoprotein (RNP) complex of highly pathogenic avian influenza virus H5N1. Influenza Other Respir. Viruses 2013, 7, 922-931. [CrossRef] [PubMed]

31. Feng, T.; Wang, Y.Y.; Su, J.; Li, Y.; Cai, X.H.; Luo, X.D. Amaryllidaceae alkaloids from Lycoris radiata. Helv. Chim. Acta 2011, 94, 178-183. [CrossRef]

32. Sun, Q.; Shen, Y.H.; Tian, J.M.; Tang, J.; Su, J.; Liu, R.H.; Li, H.L.; Xu, X.K.; Zhang, W.D. Chemical constituents of Crinum asiaticum L. Var. Sinicumbaker and their cytotoxic activities. Chem. Biodivers. 2009, 6, 1751-1757. [CrossRef] [PubMed]

33. Zhang, X.; Huang, H.; Liang, X.; Huang, H.; Dai, W.; Shen, Y.; Yan, S.; Zhang, W. Analysis of Amaryllidaceae alkaloids from Crinum by high-performance liquid chromatography coupled with electrospray ionization tandem mass spectrometry. Rapid Commun. Mass Spectrom. 2009, 23, 2903-2916. [CrossRef] [PubMed]

34. McNulty, J.; Nair, J.J.; Codina, C.; Bastida, J.; Pandey, S.; Gerasimoff, J.; Griffin, C. Selective apoptosis-inducing activity of crinum-type Amaryllidaceae alkaloids. Phytochemistry 2007, 68, 1068-1074. [CrossRef] [PubMed]

35. Liao, N.; Ao, M.; Zhang, P.; Yu, L. Extracts of Lycoris aurea induce apoptosis in murine sarcoma s180 cells. Molecules 2012, 17, 3723-3735. [CrossRef] [PubMed]

36. Kihara, M.; Konishi, K.; Xu, L.; Kobayashi, S. Alkaloidal constituents of the flowers of Lycoris radiata herb (amaryllidaceae). Chem. Pharm. Bull. 1991, 39, 1849-1853. [CrossRef]

37. Van Goietsenoven, G.; Andolfi, A.; Lallemand, B.; Cimmino, A.; Lamoral-Theys, D.; Gras, T.; Abou-Donia, A.; Dubois, J.; Lefranc, F.; Mathieu, V.; et al. Amaryllidaceae alkaloids belonging to different structural subgroups display activity against apoptosis-resistant cancer cell. J. Nat. Prod. 2010, 73, 1223-1227. [CrossRef] [PubMed]

38. Pham, L.H.; Döpke, W.; Wagner, J.; Mügge, C. Alkaloids from Crinum amabile. Phytochemistry 1998, 48, 371-376. [CrossRef] 
39. Liu, H.; Luan, F.; Ju, Y.; Shen, H.; Gao, L.; Wang, X.; Liu, S.; Zhang, L.; Sun, W.; Ma, C. In vitro transfection of the hepatitis Bvirus PreS2 gene into the human hepatocarcinoma cell line HepG2 induces upregulation of human telomerase reverse transcriptase. Biochem. Biophys. Res. Commun. 2007, 355, 379-384. [CrossRef] [PubMed]

40. Cao, M.R.; Li, Q.; Liu, Z.L.; Liu, H.H.; Wang, W.; Liao, X.L.; Pan, Y.L.; Jiang, J.W. Harmine induces apoptosis in HepG2 cells via mitochondrial signaling pathway. Hepatobiliary Pancreat. Dis. Int. 2011, 10, 599-604. [CrossRef]

Sample Availability: Samples of the compounds are not available from the authors.

(C) 2015 by the authors; licensee MDPI, Basel, Switzerland. This article is an open access article distributed under the terms and conditions of the Creative Commons by Attribution (CC-BY) license (http:/ / creativecommons.org/licenses/by/4.0/). 